\title{
Dysplasia epiphysealis hemimelica (Trevor disease) in the ankle
}

\author{
This article was published in the following Dove Press journal: \\ Therapeutics and Clinical Risk Management \\ 6 April 2016 \\ Number of times this article has been viewed
}

\author{
Firat Ozan' \\ Fatih Doğar' \\ Kaan Gürbüz' \\ Yakup Ekinci \\ Ökkeș Bilal ${ }^{3}$ \\ Eyyüp Sabri Öncel'
}

'Department of Orthopedics and Traumatology, Kayseri Training and Research Hospital, ${ }^{2}$ Department of Orthopedics and Traumatology, Develi Hatice Muammer Kocatürk State Hospital, Kayseri, ${ }^{3}$ Department of Orthopedics and Traumatology, Kahramanmaraș Sütçü İmam University Medical Faculty, Kahramanmaraș, Turkey
Correspondence: Firat Ozan Department of Orthopedics and Traumatology, Kayseri Training and Research Hospital, Sanayi Mahallesi Atatürk Bulvarı, Hastane Caddesi 38010 Kocasinan, Kayseri, Turkey

$\mathrm{Tel}+903523368884$

Fax +9035232073 I3

Email firatozan9@gmail.com

\begin{abstract}
Dysplasia epiphysealis hemimelica, also termed Trevor disease, is a rare disorder that, although benign in nature, can be locally aggressive, particularly when affecting the ankle joint, which is the joint most frequently affected, followed by the knee. The female:male ratio is $1: 3$, and it is generally diagnosed between 2 and 14 years of age. Surgical treatment with complete resection is recommended before irreversible joint damage and deformity occurs. We presented a case in which dysplasia epiphysealis hemimelica was diagnosed on the medial aspect of a right ankle joint.
\end{abstract}

Keywords: dysplasia epiphysealis hemimelica, Trevor disease, ankle, osteochondroma, epiphyseal hypertrophy

\section{Introduction}

Dysplasia epiphysealis hemimelica (DEH), also known as Trevor disease, is a rare disorder with unknown etiology. Its estimated incidence is $1: 1,000,000 .^{1-4}$ The ankle joint is most frequently affected, followed by the knee. The female:male ratio is $1: 3$, and DEH is generally diagnosed between 2 and 14 years of age. ${ }^{1-4}$

DEH was first described by Mouchet and Belot ${ }^{5}$ as "tarsomegalie" in 1926. In 1950, Trevor ${ }^{6}$ reported a case series, including ten patients and proposed the term “tarso-epiphysial aclasis". In 1956, Fairbank ${ }^{1}$ reported a case series of 14 patients and used the term "dysplasia epiphysealis hemimelica". DEH is considered a benign, asymmetrical, intra-articular mass lesion confined by epiphysis, resulting from an abnormal proliferation of cartilage tissue. ${ }^{3,4}$ We presented a case in which DEH was diagnosed at the medial aspect of the right ankle joint.

\section{Case report}

A 9-year-old girl was presented with swelling of the right ankle and pain during walking, for $>3$ months. The patient had no history of trauma, and there was pain during palpation at the medial aspect of the ankle. An osteocartilaginous mass $(2.5 \mathrm{~cm} \times 2.0 \mathrm{~cm} \times 2.0 \mathrm{~cm}$ in size $)$, localized at the distal end of the tibia and extending from the vicinity of the medial malleolus to the medial aspect of the talus, was observed using plain radiograph and computerized tomography (CT) (Figure 1).

During surgical intervention, a medial incision at the medial aspect of the medial malleolus was made, and subcutaneous tissues were explored. The lesion, of osteocartilaginous appearance and originating from the distal tibial epiphysis at medial malleolus level and extending to the medial aspect of the talus, was exposed, which destructed the medial cortex of the talus. Four large osteocartilaginous lesions were removed from the talus and ankle joint (Figure 2). Histological examination 

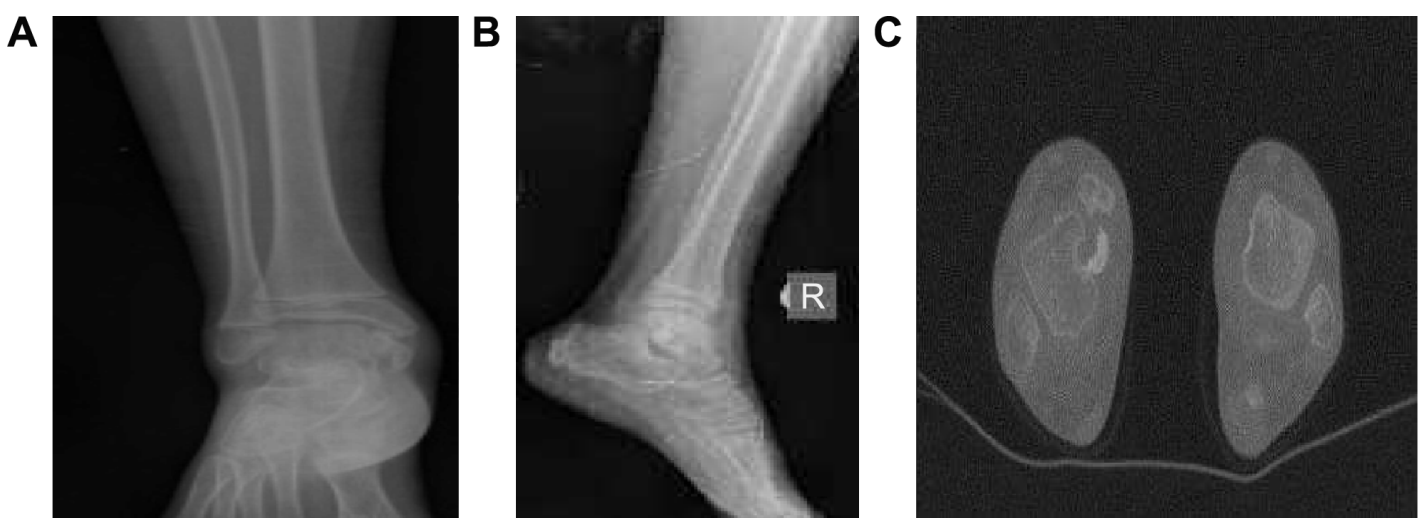

Figure I Ankle images of the patient.

Notes: Localized, irregular osseous mass at the level of anteromedial talus and medial malleolus on AP and lateral ankle radiographs (A and B). Lobulated osteocartilaginous mass appearance in the vicinity of the medial malleolus at the medial aspect of the distal tibia, right side on the axial section of CT (C).

Abbreviations: AP, anterior-posterior; CT, computerized tomography.

revealed that the lesion was mostly hyperplastic cartilage with little osseous tissue, and these features were identical to that of osteochondroma (Figure 3). However, the patient was diagnosed with DEH when the radiological and gross appearance of the lesion was compared with similar reports in the literature. ${ }^{1-9}$

During the 14-month follow-up, the patient returned to normal activities. Range of motion at the ankle was normal without pain or disability. This study was conducted in accordance with the ethical guidelines of the Declaration of Helsinki. The patient provided written informed consent before participation. The study protocol was approved by the Kayseri Training and Research Hospital, Kayseri, Turkey.

\section{Discussion}

DEH is a rare, osseous developmental disorder manifesting with epiphyseal involvement. ${ }^{3,9}$ The localized form of the disease generally involves bones in the ankle and hindfoot.
DEH is benign and its prognosis is favorable; no malignant transformation has been reported. ${ }^{4,7-9}$ The etiology of DEH is uncertain. Potential causes include a congenital error affecting the limb bud during early fetal life or the presence of abnormal chondrocytes that continue to proliferate in an unregulated manner. ${ }^{9}$

In Trevor disease, histopathological diagnosis is not pathognomonic. ${ }^{3}$ However, EXT1 and EXT2 gene expressions can be studied by additional molecular assays. ${ }^{9}$ Gene expressions are within normal ranges in DEH, whereas they are lower in osteochondroma owing to a mutation. These tests are costly; hence, clinical and radiological findings are important diagnostic tools. ${ }^{7} \mathrm{CT}$ and magnetic resonance imaging can confirm the diagnosis, aid surgical planning, and define the relationship of the mass to local structures. ${ }^{3,4,9,10}$ Specifically, CT can help define the anatomical relationship between the mass and the host bone, and magnetic resonance imaging can show the extent of epiphyseal involvement, joint deformity,
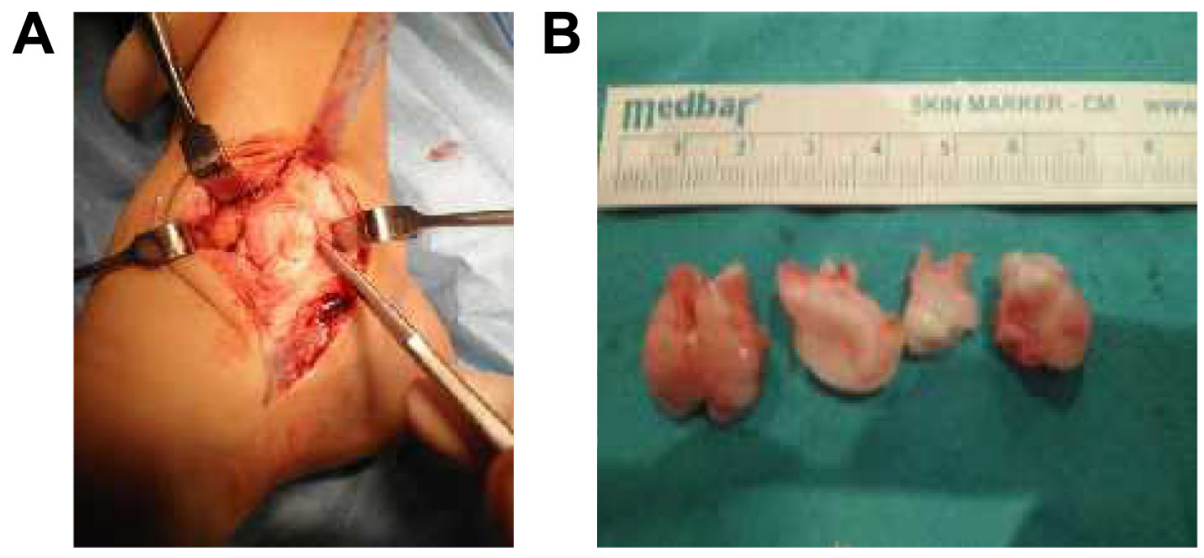

Figure 2 Intraoperative view of patient.

Notes: Intraoperative appearance of osteocartilaginous lesion at medial malleolus and anteromedial aspect of talus in the ankle (A). View of the excised osteocartilaginous lesion (B). 


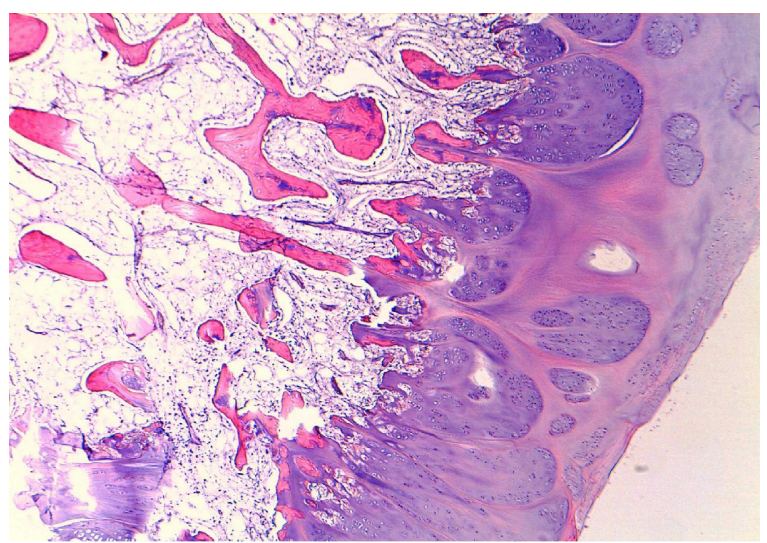

Figure 3 Histopathological findings in Trevor disease.

Notes: Superficial hyaline cartilage layer, columnar chondrocytes (right side), and mature bone trabeculae containing osseous spicules and bone marrow (left side) (hematoxylin-eosin stain, magnification 400×).

and the status of the articular surface. ${ }^{1,3,4,9}$ Radiographs usually demonstrate a partially ossified, lobulated, cartilaginous mass arising unilaterally from the affected epiphysis with or without an osseous connection. $3 ., 4,9,10$

DEH was classified by Azouz et $\mathrm{al}^{11}$ as having three distinct presentations: localized, classic, and generalized. In Trevor disease, histopathological findings are similar to those in benign osteochondroma, ${ }^{3,4,9,10}$ and it is also difficult to discriminate DEH from benign osteochondroma clinically and pathologically. ${ }^{4,10}$ Both diseases are specific to the developmental period. Thus, radiological findings are important in differential diagnosis. Irregular bone growth originating from epiphysis and a distinct ossification focus that can be seen in radiological evaluation are the most important discriminative features of Trevor disease. ${ }^{2-4,9,10}$ In addition to osteochondroma, intra-articular loose body, myositis ossificans, or synovial chondromatosis can be considered in differential diagnosis. ${ }^{3,4,9}$

Management options for Trevor disease include observation and surgical excision. Asymptomatic lesions may be treated nonoperatively, ${ }^{3,4,7,8}$ but surgery should be considered when the lesion causes pain, loss of function, limitation of movement, and deformity. $3,4,7,8$

\section{Conclusion}

In conclusion, DEH is an uncommon, benign disease. Although histopathological findings in Trevor disease are similar to those in osteochondroma, it has differential features that can be distinguished clinically and radiologically. However, molecular analysis has to be done for the definitive diagnosis. Early diagnosis and treatment are necessary to prevent articular dysfunction.

\section{Disclosure}

The authors report no conflicts of interest in this work.

\section{References}

1. Fairbank TJ. Dysplasia epiphysialis hemimelica (tarso-ephiphysial aclasis). J Bone Joint Surg Br. 1956;38(1):237-257.

2. Yurdoglu C, Sahlan S, Oklu T. Hemimelic epiphyseal dysplasia (a case report). Acta Orthop Traumatol Turc. 2004;26(5):348-349.

3. Kuo RS, Bellemore MC, Monsell FP, Frawley K, Kozlowski K. Dysplasia epiphysealis hemimelica: clinical features and management. J Pediatr Orthop. 1998;18(4):543-548.

4. Nowicki PD, Borders H. Dysplasia epiphysealis hemimelica (Trevor disease) of the ankle. Orthopedics. 2015;38(4):269-271.

5. Mouchet A, Belot J. Tarsomegalie. J Radiol Electrol. 1926;10: 289-293.

6. Trevor D. Tarso-epiphysial aclasis: a congenital error of epiphysial development. J Bone Joint Surg Br. 1950;32(2):204-213.

7. Gokkus K, Aydin AT, Uyan A, Cengiz M. Dysplasia epiphysealis hemimelica of the ankle joint: a case report. J Orthop Surg (Hong Kong). 2011;19(2):254-256.

8. Ouyang Z, Xu M, Li X, Peng D. Dysplasia epiphysealis hemimelica with involvement of the distal tibial epiphysis and talus: recurrence of a case and literature review. J Foot Ankle Surg. 2014;53(2):199-202.

9. Tyler PA, Rajeswaran G, Saifuddin A. Imaging of dysplasia epiphysealis hemimelica (Trevor's disease). Clin Radiol. 2013;68(4):415-421.

10. Struijs PA, Kerkhoffs GM, Besselaar PP. Treatment of dysplasia epiphysealis hemimelica: a systematic review of published reports and a report of seven patients. J Foot Ankle Surg. 2012;51(5):620-626.

11. Azouz RM, Slomic AM, Marton D, Rigault P, Finidori G. The variable manifestations of dysplasia epiphysealis hemimelica. Pediatr Radiol. $1985 ; 15(1): 44-49$
Therapeutics and Clinical Risk Management

\section{Publish your work in this journal}

Therapeutics and Clinical Risk Management is an international, peerreviewed journal of clinical therapeutics and risk management, focusing on concise rapid reporting of clinical studies in all therapeutic areas, outcomes, safety, and programs for the effective, safe, and sustained use of medicines. This journal is indexed on PubMed Central, CAS,

\section{Dovepress}

EMBase, Scopus and the Elsevier Bibliographic databases. The manuscript management system is completely online and includes a very quick and fair peer-review system, which is all easy to use. Visit http://www.dovepress.com/testimonials.php to read real quotes from published authors. 